\section{The easy way}

Monolith Full-Contour Zirconia from CosTech Dental Laboratory is an aesthetic, versatile zirconia option that is available to NHS patients. Priced at just $£ 29.95$ per unit, including delivery to and from the laboratory, it is the ideal way to offer your NHS patients a more aesthetic metal-free option.

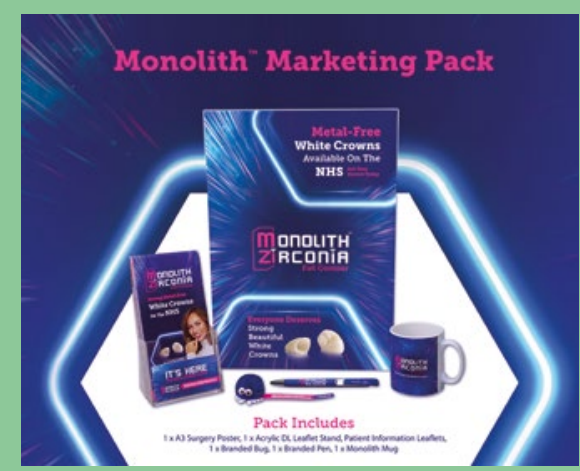

In order to promote Monolith, CosTech has put together a Marketing Pack to help ensure patients are made aware of this new opportunity as soon as they step through your door.

Including an A3 sized poster for your surgery, leaflets, a leaflet stand, branded pen, fuzzy bug and a mug, this is an excellent way to raise patient awareness.

To find out more, please contact CosTech Dental Laboratory on https://costech.co.uk/ monolith or call 01474320076.

\section{Putting patients first}

If you are thinking about selling your practice but want to make sure your patients continue to be looked after, it's important to choose your buyer carefully.

Rodericks Dental puts patients at the heart of everything it does. To ensure

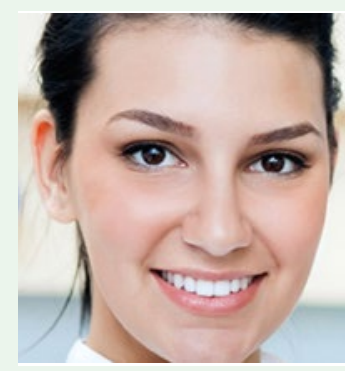

excellent patient care, it creates state-of-theart environments, prioritises professional support and career development, and uses only high quality materials and products.

The group is committed to protecting and building on your legacy in order to make

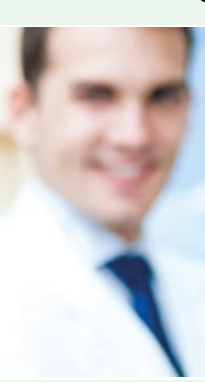
sure your patients are looked after for years to come.

For more information, sellyourdentalpractice.net or contact Rebecca Bird at acquisitions@rodericksdental. co.uk or on 01604602491 (option 5). please visit www.

\title{
Keep back to school sicknesses at bay
}

September means children will be heading back to school, presenting many more opportunities for these individuals to catch colds and other infectious illnesses.

Make sure your dental practice isn't somewhere these illnesses can spread by choosing the Steri-7 Xtra range of disinfectants from Initial Medical.

This strong formula kills over $99.9999 \%$ of pathogens including those that cause common colds and other typical school illnesses that can reside on surfaces touched by infected individuals. These disinfectants also have Reactive Barrier
Technology - innovative protection that prevents any pathogens reforming on surfaces for up to 72 hours.

For further information please visit www. initial.co.uk/medical or call 08708504045 .

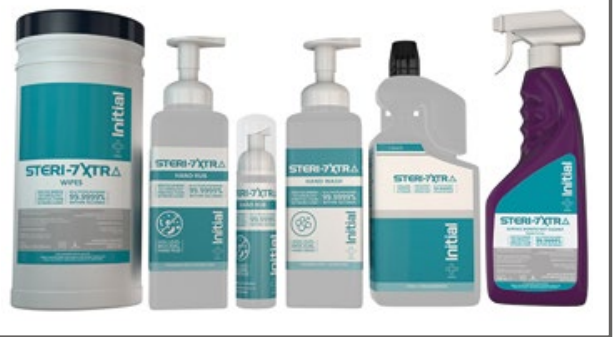

\section{Want more reviews?}

We all make buying decisions based on reviews; the same goes for patients when they are choosing a dental practice.

EasyReview Pro will generate high volumes of fresh online reviews, on the platforms of your choice - you are in control.

In just ONE month, a practice using EasyReview Pro obtained:

$\rightarrow 135$ new reviews

$\rightarrow$ A 400\% increase in Google reviews

$\rightarrow$ A $30 \%$ increase in web traffic!

We'll set it up, just sit back and watch your online reputation soar.

Contact Dental Design for full details of EasyReview Pro and to get your FREE trial by visiting https://dental-design-products. co.uk/ emailing enquiries@dental-design. co.uk or calling 01202677277 .

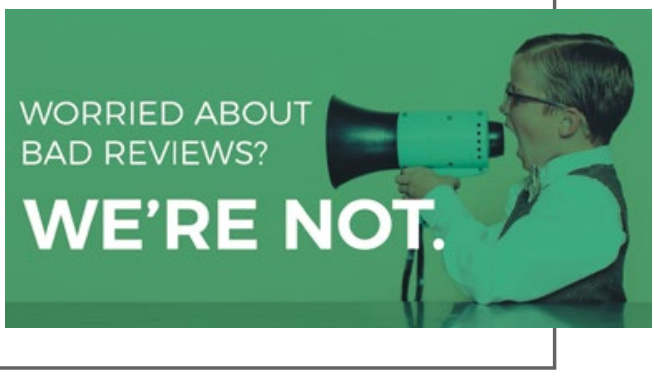

\section{Build on your skills}

Are you seeking a way into the world of dental implants? Ten Dental+Facial offers a solution with its dedicated Implant Restoration Course (IRC).

This IRC is specifically designed to give you the knowledge required to diagnose and plan implant treatment, before subsequently restoring the implant once it has been placed by a trusted clinician. A modular programme taught over a year, the IRC will cover vital aspects of implant treatment, providing hands-on experience to support essential theory.

Led by Ten Dental+Facial's Dr Nikhil Sisodia and Martin Wanendeya, the IRC provides an excellent foundation for you to build on your implantology skills.

For more information about Ten

Dental+Facial and the Implant

Restoration Course, email office@ tendental.com or call 02076227610 . 